\title{
O Processo de Inserção das Geometrias Não Euclidianas no Currículo da Escola Paranaense: a visão dos professores participantes
}

\author{
The Process of Inclusion of Non Euclidean Geometry in the School \\ Curriculum in Paraná State: the view of participating teachers
}

\author{
Marlova Estela Caldatto* \\ Regina Maria Pavanello**
}

\begin{abstract}
Resumo
Este artigo teve o objetivo de investigar como ocorreu o processo de elaboração do currículo vigente no estado do Paraná a partir da visão de professores que dele participaram, clarificando de modo especial como aconteceu a inserção das Geometrias Não Euclidianas neste currículo. Para tanto, utilizamos a História Oral e a Análise documental como metodologias. Os resultados evidenciaram que a participação dos professores não foi determinante para as decisões tomadas no processo de elaboração das Diretrizes Curriculares de Matemática e a inserção das Geometrias Não Euclidianas no documento decorreu da decisão de elemento(s) da equipe técnica de Matemática, não se sabe sob que influência.
\end{abstract}

Palavras-chave: Currículo da Escola Paranaense. Geometrias Não Euclidianas. Políticas Públicas Educacionais. História Oral e Análise Documental. Professores de Matemática.

\begin{abstract}
This paper aimed to investigate the process of developing the current curriculum in the state of Parana from the perspective of teachers who participated, especially clarifying how Non Euclidean Geometries was inserted in the curriculum. We used oral history and documentary analysis as methodologies. The results showed that teachers' participation was not decisive in the decision making during the elaboration of the Mathematics Curriculum Guidelines, and the insertion of Non Euclidean Geometry in the document followed the decision of element (s) of the technical Mathematics Team; we could not identify under what influence.
\end{abstract}

Keywords: School curriculum. Paraná. Non Euclidean Geometries. Public Policy for Education. Oral History and Document Analysis. Mathematics Teachers.

\footnotetext{
Doutoranda em Educação para a Ciência e a Matemática pela Universidade Estadual de Maringá (UEM). Professora da Universidade Tecnológica Federal do Paraná (UTFPR), Pato Branco, PR, Brasil. Endereço para correspondência: Rua Ercília Corona, nº 415, Bairro Menino Deus, CEP: 85502-300, Pato Branco, PR, Brasil. Email: marlovacaldatto@utfpr.edu.br.

Doutora em Educação pela Universidade Estadual de Campinas (UNICAMP). Docente do Programa de PósGraduação em Educação para a Ciência e a Matemática da Universidade Estadual de Maringá (UEM). Endereço para correspondência: Rua Rui Barbosa, $\mathrm{n}^{\circ}$ 625, apto 1801, Bairro Zona 07, CEP: 87020-090, Maringá, PR, Brasil.E-mail: reginapavanello@hotmail.com.
} 


\section{Introdução}

Este artigo apresenta resultados da pesquisa em nível de mestrado $^{1}$ que investigou o processo de elaboração do currículo vigente no estado do Paraná, intitulado como Diretrizes Curriculares do Paraná-Matemática ${ }^{2}$ (PARANÁ, 2008), clarificando de modo especial como ocorreu a inserção das Geometrias Não Euclidianas.

As DCE-PR Matemática ${ }^{3}$ foram elaboradas entre os anos de 2003 e 2008, na gestão de Roberto Requião ${ }^{4}$, uma elaboração conclamada pela Secretaria de Estado da Educação do Paraná $^{5}$ como oriunda de um processo de discussão coletiva, que contou com a participação efetiva dos professores da rede estadual de ensino. Este discurso não era estranho aos professores porque foi o mesmo adotado pelo peemedebista Álvaro Dias ${ }^{6}$ (1987-1990), quando assumiu o governo do Paraná, alinhando a política pública educacional ao da redemocratização da sociedade brasileira. Foi esse discurso que embasou um processo de elaboração curricular que culminou no Currículo Básico para a Escola Pública do Estado do Paraná (PARANÁ, 1992), também conhecido como CB.

A construção do CB iniciou com a adoção do Ciclo Básico de Alfabetização nos moldes daquele que estava sendo implantado no Estado de São Paulo. O governo Dias entendeu que, ao se propor um novo encaminhamento teórico-metodológico para aquisição da linguagem escrita, fazia-se "necessária a reorganização dos demais conteúdos curriculares das outras séries desse grau de ensino" (PARANÁ, 1992, p. 13).

A relação entre a origem do $\mathrm{CB}$ e Ciclo Básico de Alfabetização é contestada por Garbelini (1997), considerando que os cursos que compunham o projeto de Ciclo Básico de Alfabetização eram direcionados aos professores do ensino básico e ministrados por professores da Universidade Estadual de Campinas (UNICAMP). A proposta destes últimos não visava à reformulação curricular, seu objetivo era "uma proposta de educação em que o

\footnotetext{
${ }^{1}$ Caldatto (2011).

${ }^{2}$ Doravante a expressão $D C E-P R$ Matemática será utilizada para identificarmos as Diretrizes Curriculares do Paraná-Matemática.

${ }^{3}$ Além da disciplina de Matemática, foram contempladas com DCE-PR as seguintes disciplinas: Arte, Educação do Campo, Geografia, Filosofia, Biologia, Educação Especial, Física, História, Educação Física, Língua Estrangeira Moderna, Química, Ciências, Educação Profissional, Gênero e Diversidade, Língua Portuguesa, Educação de Jovens e Adultos, Sociologia e Ensino Religioso.

${ }^{4}$ Em 2013, cumpre seu mandado como senador pelo PMDB (Partido do Movimento Democrático Brasileiro) representando o estado do Paraná.

${ }^{5}$ A sigla SEED será utilizada, doravante, no texto para identificar a Secretaria de Estado da Educação do Paraná.

${ }^{6}$ Em 2013 cumpre seu mandado como senador pelo PSDB (Partido da Social Democracia Brasileira) representando o estado do Paraná.
} 
aluno é respeitado como indivíduo social, inserido numa estrutura social específica, falante de um dos dialetos usados no seu cotidiano" (GARBELINI, 1997, p. 29). Conforme a autora,

\begin{abstract}
A SEED, em primeira instância, interrompe as verbas para os projetos que já estavam em andamento desde os anos 1980, depois percebe que mesmo sem os recursos financeiros, alguns cursos de pós-graduação foram ministrados, grupos de estudo continuavam acontecendo. Resolve então assumir o referido trabalho e [...] os projetos originais do grupo de professores da UNICAMP não consistiam na elaboração de uma proposta curricular propriamente dita, mas sim no investimento de cursos para que os professores de posse de conhecimento e compreensão das diferentes concepções de linguagem, pudessem, por si mesmos, elaborar sua própria prática pedagógica, sem contudo, terem que seguir um manual já pronto, predeterminado (GARBELINI, 1997, p. 35-36).
\end{abstract}

O texto do CB caracteriza seu processo de elaboração como um "trabalho coletivo dos profissionais compromissados com a educação pública do Paraná” (PARANÁ, 1992, p. 13). Menciona também que esse processo contou com a participação de "educadores das escolas, das equipes de ensino dos Núcleos Regionais e das equipes de ensino do Departamento de Ensino de $1^{\circ}$ grau da Secretaria de Estado da Educação do Paraná", em "vários encontros e cursos, que visavam ao processo de análise e reestruturação dos conteúdos das áreas de conhecimento" (PARANÁ, 1992, p. 13).

A construção do $\mathrm{CB}$ a partir de um trabalho coletivo é contestada por Garbelini (1997), quando afirma que

\begin{abstract}
Não houve sistematização dos trabalhos dos professores. O que houve, de fato, foi a criação de um discurso, confuso e hermético, incompreensível aos professores que mais uma vez são manipulados e ludibriados; nega-se-lhes o direito de criarem o jeito próprio de trabalharem, ao mesmo tempo que os fazem pensar que no CB estão contidos todos os trabalhos anteriormente realizados nos grupos, nos núcleos e regiões paranaenses. (GARBELINI, 1997, p. 37).
\end{abstract}

A primeira impressão do documento ocorreu em 1990, correspondendo a 90.000 exemplares, e, no ano de 1992, houve a impressão de mais 30.000, isto já na gestão de Roberto Requião, ocorrida no período de 1991 a 1994. O CB vigorou até o ano de 1998, quando, já no governo de Jaime Lerner ${ }^{7}$, foi substituído pelos Parâmetros Curriculares Nacionais. Também conhecidos como PCN, os Parâmetros Curriculares Nacionais (BRASIL, 1998) configuram-se como um documento curricular de abrangência nacional, elaborado pelo Ministério da Educação no governo do psdbista Fernando Henrique Cardoso (1994 - 2001).

\footnotetext{
${ }^{7}$ Jaime Lerner é um político, arquiteto e urbanista, foi prefeito de Curitiba por três mandatos e governador do estado do Paraná por duas. Seu primeiro mandato como governador iniciou em 1995, quando ainda pertencia ao Partido Democrático Trabalhista (PDT). Em 1998 passa a integrar o Partido da Frente Liberal (PFL) atualmente Democratas - e é reeleito como governador do estado do Paraná, cargo que ocupou até o ano de 2002 com o término do seu segundo mandato.
} 
Essa alteração curricular não foi, no entanto, amparada pela realização de cursos de formação direcionados a sua implementação. Nesta conjuntura, o professor que, até 1998, trabalhava com o CB e estava imbuído dos objetivos e metodologias de cunho históricocrítico, passa a ter que utilizar os $\mathrm{PCN}$, documento que tem o desenvolvimento das competências como uma de suas metas.

A não indicação de conteúdos nos PCN e a falta de formação dos professores para trabalhar com esse documento os levavam a recorrerem ao $\mathrm{CB}$. O trabalho, muitas vezes concomitante, com os PCN e o CB colocava os professores em uma situação difícil, dada as orientações teóricas conflitantes entre os documentos e a indicação de conteúdos que era feita pelo CB.

No ano de 2003, com o início do governo Roberto Requião, uma política educacional é apresentada como divergente da adotada no governo anterior e tinha, como uma de suas metas, a elaboração de Diretrizes Curriculares para todas as disciplinas dos níveis fundamental e médio. Essa política reassume o discurso dos governos anteriores, de Álvaro Dias (1987 - 1990) e Roberto Requião (1991 - 1994), de que a elaboração do currículo escolar paranaense será resultado de um trabalho coletivo e de discussões realizadas com todos os professores da rede pública de ensino.

\section{Discussão metodológica}

Este artigo apresenta resultados da pesquisa cujo objetivo foi construir uma versão da história do processo de elaboração do currículo de matemática vigente no estado do Paraná DCE-PR Matemática -, considerando especialmente como ocorreu a inserção das Geometrias Não Euclidianas. A cristalização deste objeto de pesquisa se deu em razão das DCE-PR Matemática se apresentarem como "fundamento para o trabalho pedagógico na escola" (PARANÁ, 2008, p. 8) e serem propaladas pela Secretaria de Estado da Educação do Paraná como produto de uma "[...] metodologia que primou pela discussão coletiva ocorrida, efetivamente, durante os últimos cinco anos e envolveu todos os professores da rede" (PARANÁ, 2008, p. 7). O texto das DCE-PR Matemática, em um fragmento direcionado especificamente aos professores, afirma ainda que “[...] sua participação nesses eventos e suas contribuições por escrito foram fundamentais para essa construção coletiva" (PARANÁ, 2008, p. 8). 
A afirmação de que as DCE-PR Matemática foram elaboradas a partir de um processo coletivo em que os professores atuaram de forma significativa é uma fala - uma versão da história do processo de elaboração - apresentada nos discursos da Secretaria de Estado da Educação do Paraná, especialmente em documentos expedidos por esse órgão. Nesta conjuntura, não podemos deixar de mencionar Garnica (2004) ao discorrer que:

Falar de uma história "verdadeira", de uma história que "realmente aconteceu" - o
que muitas vezes fica implícito quando falamos "A" história - é desprezar a
existência de vieses alternativos, de versões outras que não as tidas como "reais",
"corretas", "verdadeiras". É, do mesmo modo, negligenciar como, por que e por
quem essa história definitiva e unívoca é constituída. Nesse rastro vem a
heroificação do "objeto" histórico (o homem é, via de regra, o diferenciado, aquele
que desponta entre os muitos comuns, em situações incomuns, despregadas do solo
das vivências cotidianas) em eventos pontuais, "momentos" cujos únicos registros
adequados (porque confiáveis), mantidos em arquivos são aqueles fixados pela
escrita (GARNICA, 2004, p. 79).

Sendo assim, nos propusemos a dar voz aos - explicitar a visão de - agentes do processo de elaboração das DCE-PR Matemática atuantes em diferentes posições do sistema educacional paranaense, a saber: dois professores da rede estadual de ensino que participaram dos encontros realizados em Curitiba e Faxinal do Céu, que foram promovidos pelo Departamento de Ensino Fundamental ${ }^{8}$ da SEED e foram disseminadores da proposta de reformulação curricular no Núcleo Regional de Educação ${ }^{9}$ de Maringá; dois professores da rede que foram somente disseminadores da proposta do DEF no NRE do município de Maringá; um professor que participou dos encontros desenvolvidos pelo Departamento de Ensino Médio ${ }^{10}$ da SEED; dois professores da rede estadual de ensino que participaram somente das atividades que foram desenvolvidas no NRE de Maringá; dois professores que durante o período compreendido entre 2003 e 2010 ocuparam o cargo de coordenador da área de Matemática no NRE de Maringá; três professores que, no período em que foram elaboradas as DCE-PR Matemática, compuseram a equipe técnico-pedagógica da disciplina de Matemática do DEF da SEED; dois professores que fizeram parte da equipe técnicopedagógica da disciplina de Matemática do DEM da SEED; e um leitor crítico da disciplina de Matemática.

\footnotetext{
${ }^{8}$ O Departamento de Ensino Fundamental da Secretaria de Estado da Educação do Paraná será identificado no texto, daqui para frente, pela sigla DEF.

${ }^{9}$ Os Núcleos Regionais de Educação (NRE) são instituições ligados a SEED, que possuem a função de gerir as instituições de ensino públicas estaduais nas diferentes regiões do estado do Paraná.

${ }^{10} \mathrm{O}$ Departamento de Ensino Médio da Secretaria de Estado da Educação do Paraná será identificado no texto, daqui para frente, pela sigla DEM.
} 
O ato de dar voz a - explicitar a visão de - agentes de um processo de elaboração de um documento com fins educacionais e de amplitude estadual foi associado por nós de imediato à História Oral, porque, segundo Alberti (2004, p. 24-25), ela "é essencialmente indicada para o estudo da história política, entendida não como história dos 'grandes homens' e 'grandes feitos' e sim como estudo das diferentes formas de articulação de atores e grupos, trazendo à luz a importância das ações dos indivíduos e de suas estratégias". Ainda conforme Alberti (2004), a História Oral também é recomendada no "estudo da forma como pessoas ou grupos efetuaram e elaboraram experiências, incluindo situações de aprendizado e decisões estratégicas" (ALBERTI, 2004, p. 25).

Em linhas gerais, a História Oral é um meio de entender como pessoas, em diferentes posições, percebem um determinado enredo, que está alocado em um tempo e um espaço relativos e esse entendimento de como pessoas e grupos experimentaram o passado "torna possível questionar interpretações generalizantes de determinados acontecimentos e conjunturas" (ALBERTI, 2004, p. 26).

O ato de optar pela História Oral, segundo Garnica (2004), significa lançar mão de uma percepção de História e reconhecer os pressupostos que a tornam possível, "é inscreverse num paradigma específico, é perceber suas limitações e suas vantagens e, a partir disso, (re)configurar os modos de agir de maneira a vencer as resistências e ampliar as vantagens" (GARNICA, 2004, p. 87). Portanto,

\footnotetext{
Não se trata simplesmente de optar pela coleta de depoimentos e, muito menos, de colocar como rivais a escrita e a oralidade. Trata-se de entender a História Oral na perspectiva de, face à impossibilidade de constituir "A" história, (re)constituir algumas de suas várias versões, aos olhos de atores sociais que vivenciaram certos contextos e situações, considerando como elementos essenciais, nesse processo, as memórias desses atores - via de regra negligenciados -, sem desprestigiar, no entanto, os dados "oficiais", sem negar a importância de fontes primárias, de arquivos, de monumentos, dos tantos registros possíveis. Não havendo uma história "verdadeira", trata-se de procurar pela verdade das histórias, (re)constituindo-as como versões, analisando como se impõem os regimes de verdade que cada uma dessas versões cria e faz valer. (GARNICA, 2004, p. 87).
}

A História Oral é entendida por Garnica (2004) como "uma expressão simplificada", porque é "a História (re)constituída a partir da oralidade, numa clara complementação (alguns prefeririam, aqui, 'oposição') àquela concepção de História pautada somente em documentos escritos ou, mais radicalmente, em fonte primárias" (p. 78).

Considerando o contexto metodológico estabelecido pela História Oral, nos propusemos a elaborar uma versão da História do processo de elaboração das Diretrizes Curriculares de Matemática, considerando as percepções de professores participantes desse 
processo e documentos expedidos pela SEED, em especial as versões publicadas e não publicadas das DCE-PR de Matemática elaboradas pelos Departamentos de Educação Básica, Ensino Fundamental e Ensino Médio, além de trabalhos acadêmicos cuja temática central foram as políticas públicas educacionais da Gestão Roberto Requião (2003 - 2010). Para o estudo das fontes escritas tivemos como referência Lakatos e Marconi (2007), por mencionarem que a pesquisa bibliográfica, ou análise bibliográfica, também pode ser entendida como um "levantamento de dados", cujo detalhamento consiste no levantamento, seleção, fichamento e arquivamento de informações relacionadas à pesquisa (2007, p. 176).

Para Meihy (2005, p. 17) a História Oral é “uma prática de apreensão de narrativas feita através do uso de meios eletrônicos e destinada a recolher testemunhos, promover análises de processos sociais do presente e facilitar o conhecimento do meio imediato". O autor classifica a História Oral como um "recurso moderno" utilizado para a produção de "documentos, arquivamento e estudos referentes à experiência social de pessoas e de grupos". E é sempre uma história do "tempo presente"11 que é também reconhecida como "história viva"12 (MEIHY, 2005, p. 15).

Para a apreensão dos testemunhos utilizamos entrevistas individuais nas quais apresentávamos ao colaborador um esboço da nossa pesquisa para que ele tivesse a clareza das informações que eram de interesse desta. O procedimento adotado alicerçou-se nas palavras de Meihy (2005), que comenta:

\begin{abstract}
A memória individual, apesar de se explicar no contexto social, é aferida por meio de entrevistas nas quais o colaborador tenha ampla liberdade para narrar. É preciso cuidado em relação às interferências presentes nas entrevistas, que podem existir ou não dependendo dos pressupostos estabelecidos no projeto. O mesmo deve ser estabelecido em relação aos estímulos, pois muitas vezes provocações podem motivar aspectos da lembrança que não emergiriam com a naturalidade das recordações. O eventual uso de estímulos deve ser apresentado ao colaborador antes das entrevistas, pois eles podem alterar a naturalidade muitas vezes buscada. (MEIHY, 2005, p. 110).
\end{abstract}

O tratamento das entrevistas se deu em duas etapas: a transcrição das entrevistas e a textualização. As transcrições ou degravações corresponderam à passagem, na íntegra, da oralidade registrada no momento das entrevistas para a forma escrita, aí incluindo tanto os vícios de linguagem, as repetições, bem como a expressão de sentimentos (risos, alteração de entonação de voz), a gestualização e os momentos de silêncio.

\footnotetext{
11 Movimento renovador da visão da história baseado na presentificação dos acontecimentos do passado. (MEIHY, 2005, p. 262).

${ }^{12}$ História feita com base nos depoimentos e de uso imediato. (MEIHY, 2005, p. 261).
} 


\begin{abstract}
Adotando o princípio elementar de que existem diferenças entre uma situação (língua falada) e outra (língua escrita), o mais importante na transposição de um discurso para o outro é o sentido, que, por sua vez, implica intervenção e desvios capazes de sustentar os critérios decisivos. Por outro ângulo, a incorporação do indizível, do gestual, das emoções e do silêncio convida a uma interferência que tenha como fundamentos a clareza do texto e sua força expressiva. (MEIHY, 2005, p. 195).
\end{abstract}

$\mathrm{Na}$ textualização das entrevistas, retiramos os vícios de linguagem, os questionamentos da entrevistadora-pesquisadora e as descrições dos fatos ocorridos no momento das entrevistas com o objetivo de "limpar" a narrativa apresentada pelos depoentes. Reordenamos o fluxo discursivo da entrevista cronologicamente e preenchemos lacunas existentes na narrativa do depoente com o objetivo de tornar o texto mais claro. (GARNICA, 2004).

Para a textualização, consideramos a descrição apresentada por Garnica (2004):

[...] uma primeira textualização consiste em livrar a transcrição daqueles elementos próprios à fala, evitando as repetições desnecessárias - mas comuns aos discursos falados - e os vícios de linguagem. Num momento seguinte, as perguntas são fundidas às respostas, constituindo um texto escrito mais homogêneo, cuja leitura pode ser feita de modo mais fluente. É também possível, nessa primeira sistematização, que o pesquisador altere a sequência do texto, optando por uma linha específica, seja ela cronológica ou temática. Os momentos da entrevista são, assim, "limpos", agrupados e re-alocados no texto escrito. (GARNICA, 2004, p. 93-94).

O produto do processo de textualização de cada entrevista foi apresentado ao depoente ao qual correspondia, para que este a apreciasse e sugerisse as alterações que considerasse necessárias. Tal procedimento teve por objetivo certificar a identificação dos entrevistados com os textos resultantes da textualização, principalmente porque nosso trabalho trata de temas políticos.

Para a exposição dos dados que obtivemos na pesquisa documental e nos depoimentos, elaboramos uma narrativa, considerando a narrativa como "uma tradição de contar um acontecimento em forma sequencial, cuja composição mais simples inclui começo, meio e fim” (REIS, 2008, p. 25).

\title{
3 A elaboração das DCE-PR Matemática, a inserção das Geometrias Não Euclidianas e a participação dos professores de matemática nesta elaboração
}

No início da sua primeira gestão no governo do Estado do Paraná, nos anos 2000, Roberto Requião nomeou o seu irmão, Maurício Requião, para o cargo de Secretário de Estado da Educação, o qual, ao assumir a Secretaria de Estado da Educação do Paraná, 
concomitantemente aos processos de definição e nomeação dos quadros de dirigentes, apresentou o que seriam algumas das prioridades em seu mandato. Dentre elas destacamos: a elaboração de uma proposta curricular para a escola pública do Paraná; a definição de um plano de carreira para professores e pedagogos da rede estadual de ensino; reformulação da política de formação docente; a construção do Projeto Político-Pedagógico ${ }^{13}$ das escolas e a construção do Plano Estadual de Educação ${ }^{14}$.

Como resultado das prioridades de Maurício Requião, em 2008 foram lançadas as Diretrizes Curriculares do Paraná-Matemática. Este documento divide-se em dois textos: “ $A$ Educação Básica e a Opção pelo Currículo Disciplinar" e "Diretrizes Curriculares da Disciplina de Matemática”.

“A Educação Básica e a Opção pelo Currículo Disciplinar Teóricos; 3. Dimensões do Conhecimento (3.1 O Conhecimento e as Disciplinas Curriculares; 3.2 A Interdisciplinaridade e 3.3 A Contextualização Sócio-Histórica); 4. Avaliação e 5. Referências. Este primeiro texto apresentado nas DCE-PR Matemática é comum às Diretrizes Curriculares de todas as disciplinas escolares.

Os textos que compõem as "Diretrizes Curriculares da Disciplina de Matemática" são específicos à disciplina de Matemática e são os seguintes: 1. Dimensão Histórica da Disciplina; 2. Fundamentos Teórico-Metodológicos; 3. Conteúdos Estruturantes (3.1 Números e Álgebra; 3.2 Grandezas e Medidas; 3.3 Geometrias; 3.4 Funções e 3.5 Tratamento da Informação); 4. Encaminhamentos Metodológicos (4.1 Resolução de Problemas; 4.2 Etnomatemática; 4.3 Modelagem Matemática; 4.4 Mídias Tecnológicas; 4.5 História da Matemática; 4.6 Investigações Matemáticas e 4.7 Articulando as Diferentes Tendências); 5. Avaliação; 6. Referências e Anexo: Conteúdos Básicos da Disciplina de Matemática. O tópico Conteúdos Estruturantes expõe que

\begin{abstract}
Entende-se por Conteúdos Estruturantes os conhecimentos de grande amplitude, os conceitos e as práticas que identificam e organizam os campos de estudos de uma disciplina escolar, considerados fundamentais para a sua compreensão. Constituemse historicamente e são legitimados nas relações sociais. Os Conteúdos Estruturantes propostos nestas Diretrizes Curriculares, para a Educação Básica da Rede Pública Estadual, são: Números e Álgebra; Grandezas e Medidas; Geometrias; Funções; Tratamento da informação. (PARANÁ, 2008, p. 49).
\end{abstract}

\footnotetext{
${ }^{13}$ De acordo com a INSTRUÇÃO N ${ }^{0}$ 007/2010 - SUED/SEED, o Projeto Político-Pedagógico (PPP) se constitui nos fundamentos legais, conceituais, filosóficos, ideológicos, metodológicos e operacionais das práticas pedagógicas no ambiente escolar.

${ }^{14}$ O Plano Estadual de Educação do Estado do Paraná (PEE PR) é um documento de planejamento e orientação das políticas públicas para a Educação Paranaense.
} 
O conteúdo estruturante Geometrias desdobra-se em Geometria Plana, Geometria Espacial, Geometria Analítica e Noções Básicas de Geometrias Não Euclidianas. Para o ensino fundamental, o conteúdo Noções de Geometrias Não Euclidianas contempla os seguintes conteúdos: Geometria Projetiva (pontos de fuga e linhas do horizonte), Geometria Topológica (conceitos de interior, exterior, fronteira, vizinhança, conexidade, curvas e conjuntos abertos e fechados) e noções de Geometria dos Fractais. Os conteúdos indicados para serem trabalhados no ensino médio relativos às Noções de Geometrias Não Euclidianas são: Geometria dos Fractais, Geometria Projetiva, Geometria Hiperbólica e Elíptica.

O documento (PARANÁ, 2008, p. 56) indica que "na Geometria dos Fractais pode-se explorar: o floco de neve e a curva de Koch; triângulo e tapete de Sierpinski” e

\footnotetext{
Para abordar os conceitos elementares da Geometria Hiperbólica, uma possibilidade é através do postulado de Lobachevsky (partindo do conceito de pseudo-esfera, pontos ideais, triângulo hiperbólico e a soma dos seus ângulos internos). Já na apresentação da Geometria Elíptica, fundamentá-la através do seu desenvolvimento histórico e abordar: postulado de Riemann; curva na superfície esférica e discutir o conceito de geodésia; círculos máximos e círculos menores; distância na superfície esférica; ângulo esférico; triângulo esférico e a soma das medidas de seus ângulos internos; classificação dos triângulos esféricos quanto à medida dos lados e dos ângulos; os conceitos referentes à superfície da Terra: polos, equador, meridianos, paralelos e as direções de movimento. (PARANÁ, 2008, p. 57).
}

As DCE-PR Matemática, definidas "como fundamento para o trabalho pedagógico na escola" (PARANÁ, 2008, p. 8), são a cristalização do Programa de Reformulação Curricular, idealizado e gestado pela Superintendência da Educação da Secretaria de Estado da Educação do Paraná, chefiada por Yvelise Freitas Arco-verde, de 2003 até meados de julho de 2008, quando substituiu Maurício Requião, que havia assumido o cargo de conselheiro do Tribunal de Contas do Estado do Paraná, na pasta da Educação.

Segundo o discurso oficial, a metodologia adotada tanto na elaboração das DCE de todas as disciplinas, quanto na do PEE, foi a construção coletiva, que pregava a elaboração do documento no interior da escola, com o envolvimento efetivo dos professores da rede estadual de ensino do Paraná, conforme o próprio documento descreve:

Sendo assim, a partir de 2003, a SEED deflagrou um processo de discussão coletiva com professores que atuam em salas de aula, nos diferentes níveis e modalidades de ensino, com educadores dos Núcleos Regionais e das equipes pedagógicas da Secretaria de Estado da Educação. O resultado desse longo trabalho conjunto passa a constituir estas Diretrizes Curriculares, as quais resgatam importantes considerações teórico-metodológicas para o ensino da Matemática. (PARANÁ, 2008, p. 47).

A elaboração das diretrizes é descrita nos textos da SEED como uma resposta à política educacional adotada pelo governo anterior, "fortemente marcada pela concepção 
neoliberal, que passou a propor para as escolas uma ação pedagógica voltada para o desenvolvimento de competências e habilidades", que provocou nas escolas "um verdadeiro bombardeio de concepções e propostas diferenciadas, sem muitas vezes estarem preparadas para o desafio de definições curriculares de formação do aluno” (PARANÁ, 2005, p. 1).

Em relação aos projetos apresentados como prioridades da gestão Maurício Requião, Arias (2007) menciona que

O PEE-PR, e demais políticas educacionais, desenvolvidas no Paraná, a partir de 2003, início da gestão peemedebista, são, a princípio, apresentadas como respostas estatais contundentes ao direcionamento privatista e gerencial a que a educação pública havia sido submetida ao longo do período lernista (1995-2002). (ARIAS, 2007, p. 73).

O Projeto de Reformulação Curricular pode assim ser mencionado como a convergência de diferentes fatores, que, naquele momento, se relacionavam entre si: o posicionamento de esquerda do governo do Estado, a sugestão do Sindicato dos Trabalhadores em Educação do Estado do Paraná e o retorno à SEED de parte dos profissionais responsáveis pela construção do Currículo Básico no final da década de 1980 e início da de 1990.

A ideia inicial era que fossem construídas duas Diretrizes Curriculares para o ensino paranaense de Matemática, uma destinada ao Ensino Fundamental e, outra, ao Ensino Médio. Assim, a partir de 2003, tanto o Departamento de Ensino Fundamental, encarregado do documento destinado a este segmento da educação básica, quanto o Departamento de Ensino Médio, também responsável pelo documento referente a este nível de ensino, desenvolveram uma série de ações destinadas a promover a construção curricular: formações continuadas, palestras, leitura e discussão de textos direcionados pelos departamentos, preenchimento de questionários pelos professores da rede, entre outras. Como resultado, ao término de 2005, haviam sido publicadas, pelo DEF, três versões do documento que seria destinado ao Ensino Fundamental e, pelo DEM, duas versões das diretrizes direcionadas ao Ensino Médio.

Ao analisarmos as versões das DCE-PR Matemática construídas pelo DEF, encontramos os conteúdos matemáticos classificados de acordo com os intitulados Eixos Matemáticos (Geometria, Números e Operações, Medidas e Tratamento da Informação), o de Geometria tratando estritamente de conteúdos relacionados à Geometria Euclidiana. 
A respeito dos primeiros documentos elaborados pelo DEF, a professora Dorotéia ${ }^{15}$, membro da equipe técnica do DEF nos anos de 2003, 2004, 2005 e início de 2006, comenta que:

E essa primeira versão que nós do DEF elaboramos foi muito criticada internamente, tanto pela densidade do material, quanto e principalmente pela recorrência que o documento fazia ao CB; uma das falas que ouvimos foi do tipo: "olha, nós não queremos que vocês peguem o $C B$ de muleta, nós queremos um documento novo". Eu penso que neste momento começou a ser descaracterizado o processo de construção coletiva, porque a alusão ao CB era feita pelos professores. (Prof. Dorotéia)

As primeiras versões elaboradas pelo DEF foram consideradas por alguns professores como mal elaboradas ${ }^{16}$, conforme explicitado em um trecho da entrevista da professora Luciana $^{17}$ :

Primeiro se faz um documento tosco [...] E quando saiu a primeira versão das DCE ninguém conseguia entender, era uma colcha de retalhos em que se aproveitou parte do CB com algumas coisas da discussão com os professores. Eu me assustei muito quando li a primeira versão, porque eu não conseguia ver ali o trabalho que a gente estava tentando começar. Foi como se alguém tivesse sentado e escrito qualquer coisa de repente, só para encher espaço. (Prof. Luciana)

Analisando as versões das DCE-PR Matemática elaboradas e publicadas pelo DEM em meados de 2005, vemos os conteúdos matemáticos classificados de acordo com os intitulados Conteúdos Estruturantes (1. Números e Álgebra; 2. Funções; 3. Geometrias; 4. Tratamento da Informação), o Conteúdo Estruturante Geometrias desdobrando-se em: Geometria plana; Geometria espacial; Geometria analítica; e Noções Básicas de Geometria Não Euclidiana. Esta é, porém, a única menção feita a esse tema, pois o texto não explica o que considera como Noções Básicas de Geometria Não Euclidiana e muito menos o que são as Geometrias Não Euclidianas.

Daniel, membro do DEM no decorrer da elaboração das DCE-PR Matemática, nos relatou que:

Especificamente sobre os conteúdos, nós do DEM tivemos a ideia de inserir o conteúdo Geometrias Não Euclidianas no texto das diretrizes, e nessas conversas que nós tivemos com os professores nós já jogávamos essa questão para eles, se eles eram favoráveis ou não eram favoráveis. No encontro de Faxinal do Céu em novembro de

\footnotetext{
${ }^{15} \mathrm{O}$ nome Dorotéia é fictício, assim como todos os outros nomes de entrevistados utilizados neste trabalho.

${ }^{16}$ O texto continha erros de grafia e vícios de linguagem como o "gerundismo", conforme verifica-se na frase a seguir: "Daqui por diante estaremos dando alguns indicativos para o trabalho com os eixos da matemática no intuito de favorecer a reflexão dos professores a respeito dos mesmos" (PARANÁ, 2005).

${ }^{17}$ Esta entrevistada é professora da rede estadual de ensino e participou de todo o processo de elaboração das DCE e, inicialmente, estava alocada no grupo de discussões do Ensino Fundamental.
} 
2004, nós já fizemos essa pergunta aos professores, e fizemos também perguntas sobre outros conteúdos, deixamos bem à vontade para os professores comentarem sobre os conteúdos que deveriam estar nesse texto de diretriz curricular [...] Nós tínhamos uma ideia fechada de não tirar conteúdos do texto das diretrizes por esse medo de ocorrer futuramente o esvaziamento dos conteúdos da disciplina de Matemática que está no núcleo comum. Então, nós colocamos a discussão em aberto sobre a possibilidade de termos as Geometrias Não Euclidianas e alguns professores foram a favor, alguns contra e esse assunto foi bastante polemico. Ainda nesse encontro, alguns professores defenderam que nós deveríamos tirar números complexos, alguns defenderam que nós deveríamos tirar polinômios, e essa conversa foi ganhando corpo, em alguns momentos a discussão foi bastante polêmica, bastante calorosa, e nós da SEED sempre fomos muito firmes no posicionamento de que não queríamos subtrair nenhum conteúdo e nós iríamos, além de não subtrair, acrescentar as Geometrias Não Euclidianas. (Prof. Daniel)

Ele justifica a opção da equipe do DEM de inserir as Geometrias Não Euclidianas:

A nossa opção pela inserção das Geometrias Não Euclidianas se deu porque acreditávamos que abordá-las no contexto do ensino e da aprendizagem matemática significaria contribuir para que o aluno ampliasse seu horizonte de conhecimento, pois tais geometrias baseiam-se na negação do quinto postulado de Euclides que aborda o conceito de paralelas. E o quinto postulado pode ser aceito como verdadeiro se considerarmos o nível plano, porém se ele estiver em uma superfície não plana pode perder a validade. E como o meio em que estamos tem porções planas e outras não planas e para estas últimas torna-se necessário explorar os conceitos matemáticos delas oriundos. (Prof. Daniel)

No tocante à participação dos professores no processo de inserção das Geometrias Não Euclidianas, o nosso entrevistado Daniel cita que:

Com relação às Geometrias Não Euclidianas não ocorreu discussão com os professores sobre os desdobramentos desse conteúdo, porque naquele momento que estávamos fazendo as discussões a preocupação era a de colocar as Geometrias Não Euclidianas no texto, em convencer os professores a aceitar essa inserção e não discutir a fundo sobre elas. (Prof. Daniel)

É importante mencionar que nenhum dos membros das equipes técnicas da SEED por nós entrevistados explicitou de onde surgiu a ideia de inclusão das Geometrias Não Euclidianas no currículo. Será que, como afirma o professor Daniel ${ }^{18}$, ela ocorreu apenas

\footnotetext{
18 Segundo o professor Daniel, os textos que alavancaram a introdução desse conteúdo foram os seguintes: "Non-Euclidean Adventures on the Lénárt Sphere - investigations in planar and spherical geometry", de I. LÉNÁRT; "Matemática e Imaginação: o mundo fabuloso da matemática ao alcance de todos", de E. KASNER e J. NEWMAN; o artigo "Atividades introdutórias às geometrias não euclidianas: o exemplo da geometria do
} 
porque isto "significaria contribuir para que o aluno ampliasse seu horizonte de conhecimento, pois tais Geometrias baseiam-se na negação do quinto postulado de Euclides que aborda o conceito de paralelas"? Ou teria apenas como objetivo a inserção de uma novidade no currículo?

A fala de Daniel evidencia que a elaboração de um currículo nunca é uma ação neutra, porque, conforme Sacristán (1998, p. 17), “os currículos são a expressão do equilíbrio de interesses e forças que gravitam sobre os sistemas educativos num dado momento, enquanto que através dele se realizam os fins da educação no sistema escolarizado".

No caso da elaboração coletiva das DCE-PR Matemática que, segundo o discurso da SEED, contou com a participação ativa dos professores da rede estadual de ensino, a inserção das Geometrias Não Euclidianas evidencia o desequilíbrio de forças presente no processo de elaboração desse documento curricular. Fica evidente ter havido apenas um processo de convencimento dos professores da importância genérica da inserção desse conteúdo no currículo sem uma discussão efetiva sobre o que são essas geometrias e as implicações do seu conhecimento para a formação dos estudantes da escola básica. Não se considerou o fato de os professores, em sua maioria, serem contrários a essa inserção devido às adversidades que a escola pública é obrigada a superar, nem se eles conheciam ou não o tema. Importava que aceitassem essa inclusão para corroborar o discurso da SEED sobre a construção coletiva das DCE-PR Matemática.

A ação de convencimento dos professores evidencia a luta de forças que ocorre no processo de estabelecimento de um currículo, embora não seja suficiente apenas se alterar o currículo para que o professor o implemente em sala de aula, porque, se ele não considerar conveniente determinada indicação feita pelo currículo, irá ignorá-la.

Nessa conjuntura, os jargões construção coletiva, processo democrático de elaboração tornam-se argumentos retóricos no equilíbrio de forças estabelecido entre o governo, que está tentando implementar um documento e possui força para fazer isso sem o consentimento dos professores, e os professores, que são as peças fundamentais para o sucesso dessa implementação. E é importante ressaltar, como salienta Sacristán (1998, p. 101), que o "currículo é um objeto que se constrói no processo de configuração,

táxi”, de A. M. KALEFF e R. S.NASCIMENTO, publicada no Boletim, Rio de Janeiro, no 44, dezembro 2004, p.11- 42 GEPEM (Grupo de Estudos e Pesquisas em Educação Matemática) e a dissertação de mestrado de Z. MARTOS, "Geometrias não euclidianas: uma proposta metodológica para o ensino de geometria no ensino fundamental". Note-se que apenas o último texto citado é que aborda uma experiência de inclusão das geometrias não euclidianas no ensino fundamental e mesmo assim em uma pesquisa, que, como é sabido, é desenvolvida sob condições especiais. 
implementação, concretização e expressão de determinadas práticas pedagógicas e em sua própria avaliação, como resultado das diversas intervenções que nele se operam".

Considerando-se o currículo como "veiculação de ideias que transmitem uma visão do mundo social vinculada aos interesses dos grupos situados em uma posição de vantagem na organização social", a SEED usufrui da vantagem de ser a idealizadora e gestora do processo de elaboração das diretrizes (MOREIRA; SILVA, 1997, p. 23).

As diferenças nos textos elaborados pelo DEF e DEM não se restringiam aos conteúdos e suas classificações, mas estendiam-se a toda estruturação dos documentos, desde o ideário político-ideológicos até a teoria da aprendizagem norteadora do documento.

No início de 2006, o secretário de Educação Maurício Requião passou a interferir no processo de elaboração das DCE por entender sua interferência como necessária dada a disparidade existente entre os documentos propostos pelo DEF e pelo DEM, documentos que iriam representar uma mesma Secretaria de Educação e um mesmo governo e em alguns casos até a mesma disciplina. Para ele, essa disparidade significava a cristalização da falta de integração entre os referidos departamentos, ocorrida desde o início da gestão, uma desconexão que provinha, principalmente, da não explicitação de uma linha teórica única para caracterizar o trabalho da Secretaria Estadual de Educação e da independência dada aos departamentos por suas chefias imediatas.

A interferência do secretário foi necessária porque a tentativa da então superintendente de educação, Yvelise Freitas de Souza Arco-Verde, de unificação dos departamentos, foi frustrada devido "a uma forte resistência dos chefes de departamento, os quais se recusaram a abandonar seus cargos" (ARIAS, 2007, p. 91).

A partir da interferência do secretário de educação, DEF e DEM foram extintos e foi criado o DEB, Departamento do Ensino Básico, cujos membros eram, quase em sua totalidade, ex-membros do DEM. Então este novo departamento passou a gestar a elaboração de um documento curricular que contemplasse tanto o Ensino Fundamental quando o Médio.

Entre os anos de 2006 e 2008, foram realizados os DEB Itinerantes, eventos promovidos pelo DEB com o intuito de fomentar, dentre outras atividades, a elaboração das Diretrizes Curriculares para todas as disciplinas escolares. Sobre os DEB Itinerantes, nossa entrevistada Jussara, que, entre os anos de 2004 e 2005, participou das discussões das DCE promovidas pelo DEF representando o Núcleo Regional de Educação do Paraná - Maringá, nos explicita que: 
Nós não sentamos para afunilar conteúdo, não foi feita essa discussão. Essa discussão foi feita em 2008, quando a SEED começou a enviar para os núcleos regionais representantes para discutirem os conteúdos estruturantes e conteúdos especificos, mas já com a listagem de conteúdos pronta dentro de uma "nova" versão das DCE. Perguntavam se nós concordávamos ou discordávamos, se queríamos mudar de série algum conteúdo, mas discussão sobre aqueles conteúdos que hoje são os conteúdos estruturantes das diretrizes, se deveriam ser alterados, acrescidos ou retirados não foi feita. Se foi feita, foi para o ensino médio, porque para o ensino fundamental, onde eu participei, não aconteceu [...] Se fôssemos pensar nas discussões em torno dos conteúdos, eu voltaria mais para trás um pouco, voltaria para a pergunta: o que é conteúdo estruturante? Essa foi a primeira pergunta dos professores, porque não havia sido discutido isso.

Sobre a inserção das Geometrias Não Euclidianas eu não sei o que te falar, porque para o Ensino Fundamental, essa discussão não foi feita com nós, professores da rede. Eu fui saber que elas iriam estar nas DCE nos DEB Itinerante promovidos depois de 2006. Até porque esses eventos tinham apenas um cunho de apresentação das DCE e não de discussão em torno de sua alteração. (Prof ${ }^{\mathrm{a}}$. Jussara)

A fala da nossa entrevistada evidencia que, apesar de sua participação nos eventos propostos pela SEED durante a elaboração das DCE-PR Matemática, ela, assim como grande parte dos professores do NRE de Maringá presentes no evento do DEB Itinerante, não conheciam um dos principais elementos das diretrizes, os "conteúdos estruturantes", que correspondem ao principal objeto de trabalho dos professores, os conhecimentos matemáticos (PARANÁ, 2008).

Sua fala converge, ainda, com a análise que efetuamos das versões propostas pelo DEF, com o depoimento de Daniel e de outros sete de nossos entrevistados, da existência, em um primeiro momento, das Geometrias Não Euclidianas somente nas DCE do Ensino Médio e sua ausência nas versões do DEF e, especialmente, nas discussões propostas por esse departamento. Ou seja, a inserção desse tema se deu a partir de uma ação isolada de um grupo de membros da SEED, principalmente membros da área de matemática do extinto DEM, e não a partir da vontade, e nem sequer com a anuência dos professores de matemática de rede pública de ensino do Paraná.

Em sua fase final de elaboração, as DCE-PR Matemática passaram pelo parecer dos intitulados "especialistas" 19 (PARANÁ, 2008), professores de Programas de Pós-Graduação da área de Educação Matemática. No tocante aos conteúdos, a especialista Célia menciona que:

\footnotetext{
19 Ao término da construção das DCE-PR Matemática, este documento passou pela leitura crítica de três professores doutores que fazem parte do corpo docente de programas de pós-graduação em Educação Matemática. Esses professores foram nominados como Especialistas.
} 
O que nós fizemos, eu e o professor Valdemar ${ }^{20}$, foi especificar o que seriam essas noções de Geometrias Não Euclidianas, porque quando o documento chegou até mim ele tinha apenas o tópico "Noções de Geometrias Não Euclidianas com poucas considerações a respeito”. (Prof ${ }^{\mathrm{a}}$. Dra. Célia)

Embora haja motivos razoavelmente convincentes para a inserção das Geometrias Não Euclidianas nas DCE-PR de Matemática, ela torna-se questionável ao considerarmos as reais condições para o desenvolvimento desse conteúdo em sala de aula, como mencionado pelos professores:

E com a necessidade de se selecionar conteúdos, um dos conteúdos que provavelmente vai ser deixado de ensinar são as Geometrias Não Euclidianas, porque falta formação para o professor e assim ele não se sente seguro para trabalhar esse conteúdo, falta tempo para trabalhar todos os conteúdos indicados pelas DCE-PR Matemática, e falta material que auxilie o trabalho com esse conteúdo, porque grande parte dos livros didáticos não o contempla. E com certeza, se o professor precisar fazer uma seleção dentro de um rol de conteúdos considerando o que ele pensa ser importante para trabalhar com seu aluno, as Geometrias Não Euclidianas vão ser deixadas de lado.

Se pensarmos em sistemas não convencionais de ensino, o Ensino das Geometrias Não Euclidianas se torna mais inviável ainda. Na EJA, por exemplo, que é onde eu atuo agora (2010), a carga horária é ainda menor, então nós somos obrigados a selecionar mais ainda os conteúdos. Além disso, o aluno da EJA quer aprender conhecimentos que ele possa aplicar no cotidiano, ele quer saber o porquê ele está aprendendo aquilo, ele não se contenta apenas em saber o conteúdo, ele quer aplicar o que ele aprendeu nas suas ações do dia a dia, por isso as Geometrias Não Euclidianas acabam sendo colocadas de lado pelo aluno não as considerarem interessantes. E dessa forma as Geometrias Não Euclidianas vão ser deixadas de lado, tanto pela seleção do professor quanto pela seleção dos alunos, seleção do que eles consideram importante aprender, não tem como dizer que não, porque na grande maioria das situações ela vai se deixada de lado. (Prof ${ }^{\mathrm{a}}$. Letícia ${ }^{21}$ )

A fala da professora é pertinente, especialmente se levarmos em consideração que grande parte dos professores de Matemática atuante na rede estadual de ensino do Paraná possui grande dificuldade em trabalhar com a Geometria Euclidiana e que, muitas vezes, este conhecimento acaba não sendo trabalhado pelos professores nas escolas, mesmo a Geometria Euclidiana sendo um conhecimento presente nos currículos das Licenciaturas em Matemática.

\footnotetext{
${ }^{20}$ O professor Valdemar não fazia parte do corpo de especialista convidados para fazerem a leitura crítica das DCE-PR Matemática, porém, a professora Célia o consultou quanto aos conteúdos das Geometrias Não Euclidianas, considerando que este professor atua, dentre outras, nas áreas de Educação Matemática e ensino das Geometrias Não Euclidianas.

${ }^{21}$ A professora Letícia é professora no educação básica a mais de 25 anos, participou do processo de elaboração das DCE de Matemática como membro do Grupo Permanente de Trabalho e seus relatos são referentes aos encontros realizados pelo DEF entre os anos de 2004 e 2005. E ainda sobre os encontros realizados pelo DEB nos anos de 2007 e 2008.
} 
As dificuldades dos professores em trabalhar a Geometria Euclidiana na escola básica é amplamente discutida, conforme verificamos nas pesquisas de Pavanello $(1989,1993)$, Perez (1991), Lorenzato (1993, 1995), Fiorentini, Miguel e Miorim (1993), Gazire (2000), Passos (2000), Nacarato e Passos (2003), Vasconcellos (2008) e Santos (2009).

Santos (2009), que tinha como objeto de pesquisa a aprendizagem das Geometrias Não Euclidianas por professores de matemática da escola básica, evidencia em seus resultados que eles constantemente equivocavam-se em relação aos conteúdos da Geometria Euclidiana, o que dificultava a aprendizagem das Geometrias Não Euclidianas.

No tocante à formação inicial de professores de matemática sobre as Geometrias Não Euclidianas, Caldatto e Pavanello (2011), em pesquisa realizada no ano de 2010, na qual analisaram a grade - e suas respectivas ementas- de 24 cursos de graduação em Licenciatura em Matemática de instituições de ensino do estado do Paraná, evidenciam que "nenhum dos cursos analisados fornece aos seus graduandos uma formação matemática mínima no tocante às Geometrias Não Euclidianas (considerando-se as indicações feitas pelas DCE-PR de Matemática)" (CALDATTO; PAVANELLO, 2011, p. 9).

Além da preocupação com a formação do professor, a carga horária necessária para os professores trabalharem esse conteúdo também é um complicador para a inserção das Geometrias Não Euclidianas, conforme evidencia a fala de nossa entrevistada Marcela:

Discutimos bastante a diminuição da carga horária e dentro dessa discussão nós vimos sair da grade o desenho geométrico que era uma disciplina que nos auxiliava na falta do tempo, porque nós trabalhávamos uma boa parte dos conteúdos da Geometria Euclidiana plana nas aulas dessa matéria. Então, além de extinguirem com o desenho geométrico vieram as Geometrias Não Euclidianas, que para mim, por exemplo, eram desconhecidas. (Prof ${ }^{\mathrm{a}}$. Marcela)

A carga horária escassa foi uma constante nas falas dos professores nos encontros com a SEED, porque esta vem diminuindo gradativamente, enquanto os conteúdos constantes no currículo são mantidos em sua integralidade, o que já não lhes permite trabalhar todos os conteúdos nele indicados. Esta objeção foi, porém, completamente desconsiderada pela equipe técnica responsável pela elaboração das DCE-PR de Matemática, que inseriu conteúdos no currículo escolar do estado, como as Geometrias Não Euclidianas, por exemplo. 


\section{Consideração Finais}

Mediante o material analisado, constatamos que os professores participaram do processo de elaboração das DCE-PR Matemática, porém sua participação não foi decisiva para as decisões tomadas nessa elaboração. As informações obtidas na pesquisa nos permitem concluir que os professores tiveram contato com vários textos preliminares das DCE-PR Matemática elaborados pela SEED, porém suas contribuições não são perceptíveis neles. Observam-se de documento para documento alterações que visam apenas a uma melhor apresentação, seja do ponto de vista teórico ou de sua redação.

A análise atenta dos documentos e das falas dos entrevistados nos leva a pensar que essa participação nada mais foi do que parte de um jogo retórico promovido pelo Governo do Estado, por intermédio da SEED, com o objetivo de proporcionar aos professores um sentimento de valorização profissional e, ao mesmo tempo, evidenciar sua posição contrária à do governo Lerner, cujas políticas educacionais eram consideradas, por Roberto Requião, de inspiração neoliberal.

Os professores, desde seu ingresso, em 2003, no processo de elaboração das DCE-PR Matemática, participaram das várias atividades promovidas pela SEED, por meio de seus departamentos (DEF, DEM ou DEB). Contudo, o que foi produzido pelos professores no decorrer dessas atividades não foi considerado no decorrer da elaboração das DCE-PR de Matemática, especialmente, solicitações sobre temas do cotidiano dos professores de matemática, como: alterações nos conteúdos matemáticos tradicionais da escola básica, e a relação baixa carga horária da disciplina de Matemática versus o extenso rol de conteúdos a serem ministrados nessa disciplina. E é essa a visão que os professores têm do processo.

No tocante aos conteúdos estruturantes, as principais alterações a esse respeito - como a inserção das Geometrias Não Euclidianas, por exemplo - ficaram a cargo da equipe técnica de Matemática da SEED, e a participação dos professores nas discussões ficou limitada, como eles mesmos apontam, à distribuição, entre as séries, de um rol de conteúdos previamente estabelecido pela equipe técnica da SEED.

No que diz respeito às Geometrias Não Euclidianas, nossa análise mostrou ainda que sua introdução se concretiza a partir do momento em que as equipes do DEM e DEF, até então trabalhando em documentos separados, se fundiram. Com a unificação das equipes, a influência do DEM na condução do processo de elaboração das DCE-PR Matemática se 
cristalizou, e as Geometrias Não Euclidianas, que já faziam parte do currículo que estava sendo construído para o ensino médio, passaram a integrar também o currículo do ensino fundamental. $\mathrm{O}$ processo de convencimento dos professores a anuir à decisão tomada pela equipe do DEM ampliou-se, atingindo os professores de matemática da rede estadual de ensino de modo geral. Este incidente mostra bem como o discurso da construção coletiva passou ao largo de sua efetivação, conforme os professores que deste processo de elaboração e a análise das versões preliminares das DCE-PR Matemática evidenciaram.

O que nos leva à discussão sobre as condições reais de implementação das alterações propostas nas DCE-PR Matemática. Para que esta fosse viável, seria necessário que a SEED se dispusesse a efetivar um programa voltado especificamente à formação continuada dos professores da rede em relação ao tema Geometrias Não Euclidianas, o que não vem ocorrendo, até porque alterou-se novamente a sigla presente no governo do estado e com isso as políticas públicas educacionais estão sendo alteradas novamente. No entanto, sem esta providência, acreditamos ser impossível evitar a profecia já anunciada pelos próprios professores: a não abordagem desse tema em sala de aula.

\section{Referências}

ALBERTI, V. Ouvir contar: textos em história oral. Rio de Janeiro: Fundação Getúlio Vargas, 2004.

ARIAS, V. A. Construção política do Plano Estadual de Educação do Paraná na gestão 20032006: controvérsias acerca do processo democrático no espectro do Estado contemporâneo. 2007. 189 f. Dissertação (Mestrado em Educação) - Setor de Educação, Universidade Federal do Paraná, Curitiba, 2007.

BRASIL. Ministério da Educação. Parâmetros Curriculares Nacionais. Brasília, 1998.

CALDATTO, M. E. O processo coletivo de elaboração das Diretrizes Curriculares para a Educação Básica do Paraná e a inserção das Geometrias Não Euclidianas. 2011. 261 f. Dissertação (Mestrado em Educação para a Ciência e a Matemática) - Centro de Ciências Exatas. Universidade Estadual de Maringá, Maringá, 2011.

CALDATTO, M. E.; PAVANELLO, R. M. As Geometrias Não-Euclidianas, presentes no currículo da Escola Básica e ausentes nas licenciaturas em Matemática do Estado do Paraná. In: SEMINÁRIO INTERNACIONAL DE EDUCAÇÃO MATEMÁTICA, 3., 2011, São Paulo. Anais do III SEMINÁRIO INTERNACIONAL DE EDUCAÇÃo MATEMÁTICA... São Paulo: SIEMAT, 2011, p. 1-10. CD-ROM.

FIORENTINI, D.; MIGUEL, A.; MIORIM, M. A. Ressonância e dissonância do movimento pendular entre álgebra e geometria no currículo escolar brasileiro. Zetetiké, Campinas, v. 1, n. 1, p. 19-39, mar. 1993. 
GARNICA, A. V. M. História oral e educação matemática. In: BORBA, M. C.; ARAUJO, J. L. (Org.). Pesquisa qualitativa em educação matemática. Belo Horizonte: Autêntica, 2004. p. 77-98.

GARBELINI, S. Do currículo básico ao livro didático: uma história de contradições no Paraná. 1997. 94 f. Dissertação (Mestrado em Educação) - Faculdade de Educação, Universidade Estadual de Campinas, Campinas, 1997.

GAZIRE, E. S. O não resgate das geometrias. 2000. 217 f. Tese (Doutorado em Educação) Faculdade de Educação, Universidade Estadual de Campinas, Campinas, 2000.

LAKATOS, E., M.; MARCONI, M., de A. Fundamentos de metodologia científica. São Paulo: Atlas, 2007.

LORENZATO, S. Os por quês matemáticos dos alunos e as respostas dos professores. Pró-posições, Campinas, v. 4, n.1, p. 73-77, mar. 1993.

LORENZATO, S. Por que não ensinar geometria? Educação Matemática em Revista, São Paulo, v. 4, p. 3-13, jan./jun. 1995.

MEIHY, J. C. S. B. Manual de história oral. 5. ed. São Paulo: Edições Loyola, 2005.

MOREIRA, A. F. B.; SILVA, T. T. (Org.). Currículo, cultura e sociedade. São Paulo: Cortez, 1997.

NACARATO, A. M.; PASSOS, C. L. B. A geometria nas séries iniciais: uma análise sob a perspectiva da prática pedagógica e da formação de professores. São Carlos: EdUFScar, 2003.

PARANÁ (Estado). Secretaria de Estado da Educação. Currículo Básico para a Escola Pública do Estado do Paraná. Curitiba, 1992.

PARANÁ (Estado). Superintendência de Educação. Departamento de Ensino Fundamental. Diretrizes curriculares da educação fundamental da rede de educação básica do Estado do Paraná.

Curitiba, 2005.

PARANÁ (Estado). Superintendência de Educação. Diretrizes Curriculares da Educação Básica Matemática. Curitiba, 2008.

PASSOS, C. L. B. Representações, interpretações e prática pedagógica: a geometria na sala de aula. 2000. 398 f. Tese (Doutorado em Educação) - Faculdade de Educação, Universidade Estadual de Campinas, Campinas, 2000.

PAVANELLO, R. M. O abandono do ensino de geometria: uma visão histórica. 1989. $195 \mathrm{f}$. Dissertação (Mestrado em Educação) - Faculdade de Educação. Universidade Estadual de Campinas, Campinas, 1989.

PAVANELLO, R. M. O abandono da geometria no Brasil: causas e consequências. Zetetiké, Campinas, v.1, n. 1, p. 7-17, mar. 1993.

PEREZ, G. Pressupostos e reflexões teóricas e metodológicas da pesquisa participante no ensino de geometria para as camadas populares. 1991. 348 f. Tese (Doutorado em Educação) - Faculdade de Educação, Universidade Estadual de Campinas, Campinas, 1991. 
REIS, P. R. dos. As narrativas na formação de professores e na investigação em educação. Nuances: estudos sobre educação, Presidente Prudente, v. 15, n. 16, p. 17-34, jan./dez. 2008.

SACRISTÁN, J. G. O currículo: uma reflexão sobre a prática. Porto Alegre: ArtMed, 1998.

SANTOS, T. S. dos. A inclusão das geometrias não euclidianas no currículo da educação básica. 2009. 138 f. Dissertação (Mestrado em Educação para a Ciência e a Matemática) - Centro de Ciências Exatas. Universidade Estadual de Maringá, Maringá, 2009.

VASCONCELLOS, M. A diferenciação entre figuras geométricas não planas e planas: o conhecimento dos alunos das séries iniciais do ensino fundamental e o ponto de vista dos professores. Zetetiké, Campinas, v. 16, n. 30, p. 77-106, jul./dez. 2008. 